\title{
Simultaneous Removal of PAHs and Metal Contaminants from Water using Magnetic Nanoparticle Adsorbents
}

\author{
Yuxiong Huang ${ }^{\dagger}$, Aaron N. Fulton ${ }^{\ddagger}$, and Arturo A. Keller ${ }^{* \dagger}$ \\ ${ }^{\dagger}$ Bren School of Environmental Science and Management, University of California at \\ Santa Barbara, CA, USA 93106 \\ ${ }^{\ddagger}$ Department of Molecular, Cellular, and Developmental Biology, University of California, \\ Santa Barbara, CA, USA 93106 \\ *Corresponding author. Tel: +1805893 7548; fax: +1 805893 7612. Email address: \\ keller@bren.ucsb.edu
}




\section{Abstract}

2 Many industrial wastewaters are contaminated with both heavy metal ions and organic

3 compounds, posing a major threat to public health and the environment. In this study,

4 magnetic nanoparticle adsorbents, namely Mag-PCMA-T, which contain a maghemite

5 core and a silica mesoporous layer that permanently confines surfactant micelles within

6 the mesopores, were synthesized to achieve simultaneous removal of polycyclic aromatic

7 hydrocarbons (PAHs) $(1 \mathrm{mg} / \mathrm{L})$ and metal contaminants $(1 \mathrm{mg} / \mathrm{L})$. The individual removal

8 efficiency of $\mathrm{Cd}^{2+}$ and acenaphthene using Mag-PCMA-T was evaluated under a range of

9 initial ion concentrations and adsorbent dosages, as well as the competitive adsorption

10 with $\mathrm{Cd}^{2+}$ and acenaphthene simultaneously present. The isotherms and kinetics of $\mathrm{Cd}^{2+}$

11 and acenaphthene sorption onto Mag-PCMA-T were determined. Mag-PCMA-T

12 removed $>85 \%$ of the acenaphthene in less than $30 \mathrm{~min}$, with relatively high sorption

13 capacity (up to $1060 \mathrm{mg} / \mathrm{kg}$ ). Mag-PCMA-T also exhibited high sorption capacity for Cd-

$4^{2+}$ (up to $2250 \mathrm{mg} / \mathrm{kg}$ ). The simultaneous sorption performance was stable across a wide

$15 \mathrm{pH}$ range (4-9) as well as in the presence of competitive metal ions $\left(\mathrm{Ca}^{2+}\right.$ and $\left.\mathrm{Mg}^{2+}\right)$ or

16 natural organic matters. The Mag-PCMA-T can be regenerated and reused, providing a

17 sustainable, fast, convenient, and efficient approach for water treatment. 


\section{Keywords}

20 Nanoparticle; Magnetic separation; PAHs; Metal Contaminants; Simultaneous removal.

\section{1. Introduction}

22 Persistent organic pollutants (POPs) such as polycyclic aromatic hydrocarbons (PAHs)

23 and potentially toxic metal ions (Hübner et al., 2010) such as cadmium (Cd), pose a

24 significant threat to public health and the environment due to their high toxicity and long

25 persistence (Huang and Keller, 2015; Su et al., 2014; Su et al., 2016; Su et al., 2015; Vela et

26 al., 2012). Numerous sites are contaminated by both PAHs and heavy metals, including

27 e-wasting processing sites (Luo et al., 2011), manufactured gas plant sites (Thavamani et

28 al., 2012), and river sediments (Feng et al., 2012), which require simultaneous remediation

29 of PAHs and heavy metals. However, most recent studies have focused on the

30 decontamination of PAHs (Chen et al., 2015; Lee et al., 2015) or heavy metals (Huang et

31 al., 2014; Sargin et al., 2015) individually. Recently, more attention has been directed to

32 the simultaneous removal of both heavy metals and organic contaminants from aquatic

33 systems (Hung et al., 2016; Lalhmunsiama et al., 2016; Liu et al., 2016; Luo et al., 2016;

34 Ma et al., 2016a; Ma et al., 2016b; Zhang et al., 2016).

35 Surfactants can enhance the removal efficiency of hydrophobic organic compounds

36 (HOCs) (Wang and Keller, 2008c) including PAHs and pesticides (Clark and Keller, 
37 2012b) via micelles, which offer a good hydrophobic environment into which HOCs can

38 partition (Wang and Keller, 2008a). Surfactants can also be used for metal contaminant

39 remediation via complexation reactions and electronic interaction (Mulligan et al., 1999).

40 Song et al. (2008) investigated simultaneous removal of phenanthrene and $\mathrm{Cd}$ from

41 contaminated soils by a plant-derived biosurfactant, and demonstrated that phenanthrene

42 was desorbed from soils by the partitioning of phenanthrene into surfactant micelles while

43 Cd was removed via forming complexes with the external carboxyl groups of the micelle.

44 However, one major drawback of directly applying surfactant for aquatic systems and soil

45 remediation is the non-specific binding of the surfactants to clays and the organic matter

46 naturally present (Wang and Keller, 2008b), which would cause the displacement and

47 subsequent loss of the surfactant molecules during treatment (Hanna et al., 2002).

48 Thus, we developed magnetic permanently confined micelle arrays (Mag-PCMAs) with

49 a maghemite core and a silica porous layer that permanently confines surfactant micelles

50 within the mesopores, which would reduce surfactant loss during use (Wang and Keller,

51 2008c). Featured as magnetic nanoparticle adsorbents, Mag-PCMAs can be separated from

52 solution by applying an external magnetic field and regenerated and reused (Adeleye et al.,

53 2016). Based on the high removal performance Mag-PCMAs for the remediation of HOCs

54 (Wang and Keller, 2008c), pesticides (Clark and Keller, 2012b), natural organic matter

55 (Wang et al., 2011), oxyanions (Clark and Keller, 2012a) and emerging organic 
56 contaminants (Huang et al., 2016; Huang and Keller, 2013) in our previous studies, we

57 propose using Mag-PCMAs coupled with a nonionic surfactant, Triton X-100, for the

58 simultaneous removal of PAHs and metal contaminants. In this study, acenaphthene and

59 cadmium were selected to represent PAHs and metal contaminants, respectively, to study

60 their sorption isotherms and kinetics onto Mag-PCMAs in aqueous solution. In addition to

61 characterizing their individual sorption, the simultaneous removal of acenaphthene and

62 cadmium was investigated. Furthermore, the influence of $\mathrm{pH}$, water hardness $\left(\mathrm{Ca}^{2+}, \mathrm{Mg}^{2+}\right)$,

63 and natural organic matter (NOM) on the performance of acenaphthene and cadmium

64 sorption by the synthesized adsorbent was evaluated.

65 2. Experimental

66 2.1. Chemicals

67 Maghemite (iron (III) oxide) nanoparticles (30 $\mathrm{nm}$ in diameter) were purchased from

68 Alfa Aesar (USA). Tetramethyl ammonium hydroxide (TMAOH) (25 wt \% in water),

69 Triton X-100, ammonia (28\%), methanol, tetraethyl orthosilicate (TEOS), were purchased

70 from Sigma-Aldrich (USA). Acenaphthene (99\% pure) was purchased from Acros

71 Organics (Geel, Belgium). Cadmium chloride anhydrous, calcium chloride dehydrate, and

72 magnesium chloride were purchased from Fisher Scientific (USA). Standard Suwannee

73 River NOM was obtained from the International Humic Substances Society (IHSS, USA).

74 NOM stock solution (100 mg/L) was prepared by mixing a known amount of NOM with 
75 deionized water (DI water) for $24 \mathrm{~h}$. The $\mathrm{pH}$ of the stock solutions was then adjusted to 8

76 with $0.1 \mathrm{M}$ and $0.01 \mathrm{M} \mathrm{NaOH}$ and $\mathrm{HCl}$. All chemicals were used as received, without

77 further purification. All solutions were prepared with deionized water $(18 \mathrm{M} \Omega-\mathrm{cm})$ from a

78 Barnstead NANOpure Diamond Water Purification System (USA).

79 2.2. Synthesis of Mag-PCMA

80 The core-shell structured Mag-PCMA were synthesized through a solvothermal

81 reaction, which is a cooperative assembly of silica oligomers and surfactants onto the

82 maghemite nanoparticles, as illustrated in Figure 1. Maghemite nanoparticles $(0.1 \mathrm{~g})$ were

83 dispersed in $40 \mathrm{~mL}$ of TMAOH solution under constant mixing overnight as pre-treatment

84 to activate the surface, which would help to generate a negative charge on the maghemite

85 particles surface resulting in better binding of silicate and surfactant. The TMAOH-treated

86 maghemite nanoparticles were washed thoroughly with ethanol. Then $1.5 \mathrm{~mL}$ of Triton

$87 \mathrm{X}-100$, nonionic surfactant was added to maghemite redispersed in water and ethanol in a

88 volumetric ratio of 1:6 under constant stirring. Five $\mathrm{mL}$ of $28 \%$ ammonium hydroxide was

89 added for base-catalyzed sol-gel hydrolysis along with $1 \mathrm{~mL}$ of TEOS to bind the

90 surfactant onto the magnetic iron core. The mixture was stirred for $2 \mathrm{~h}$ at room temperature

$91\left(22-25^{\circ} \mathrm{C}\right)$. This method was adapted from the synthesis of Mag-PCMAs reported in a

92 previous study (Huang and Keller, 2013). To distinguish it from Mag-PCMA synthesized

93 with other surfactants, this material is denominated Mag-PCMA-T, for Triton X-100. 

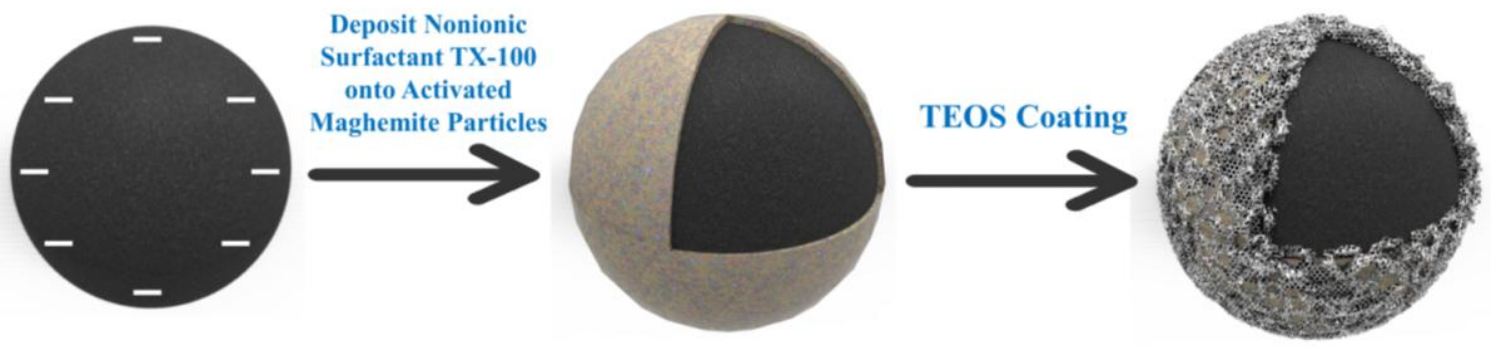

95 Figure 1. Schematic representation of Mag-PCMA-T synthesis (note: the core and shell

96 are not drawn to scale).

\subsection{Characterization of Mag-PCMA}

98 Transmission electron microscopy (TEM) images were obtained using a JEOL 1230

99 Transmission Electron Microscope operated at $80 \mathrm{kV}$. Thermogravity measurements were

100 used to investigate the amount of surfactant confined on magnetic particle adsorbents;

101 thermogravimetric analyses (TGA) were carried out on a Mettler Toledo TGA/sDTA851e

102 apparatus under an air flow of $100 \mathrm{~mL} / \mathrm{min}$ with a heating rate of $5^{\circ} \mathrm{C} / \mathrm{min}$. Magnetization

103 measurements were performed on a Quantum Design MPMS 5XL superconducting

104 quantum interference device (SQUID) Magnetometer. The zeta potential was measured

105 using a Malvern Zetasizer (Nano-ZS; Malvern Instruments, Southborough, MA) with pH

106 ranging from 4 to 10.

\subsection{Batch sorption of PAHs and metal ions}

108 For the individual isothermal experiments 5.0 mg of Mag-PCMA-T particles were mixed

109 with $20 \mathrm{~mL}$ of acenaphthene $(1 \mathrm{mg} / \mathrm{L})$ or cadmium $\left(\mathrm{Cd}^{2+}\right)$ solution $(1 \mathrm{mg} / \mathrm{L})$ in $20 \mathrm{~mL}$ glass

110 vials or $50 \mathrm{~mL}$ conical tubes, respectively, and the $\mathrm{pH}$ was adjusted to the desired condition 
111 (range from 4 to 10 ) by using $0.1 \mathrm{M} \mathrm{NaOH}$ and $0.01 \mathrm{M} \mathrm{HCl}$. Then, these tubes or vials

112 were placed in an end-over-end shaker on a Dayton-6Z412A Parallel Shaft (USA) roller

113 mixer with a speed of $70 \mathrm{rpm}$ at room temperature for $24 \mathrm{~h}$ to ensure sufficient equilibration

114 time. The variation in $\mathrm{pH}$ before and after the experiments is indicated in Table $\mathrm{S} 1$.

115 Adsorption kinetics studies were carried out at the same conditions as individual

116 isothermal experiments but for a set amount of time, varying from $1 \mathrm{~min}$ to $24 \mathrm{~h}$, with

$117 \mathrm{pH}=7$. After this mixing, the Mag-PCMA-T particles were separated from the mixture with

118 an Eclipse magnet. All experiments were conducted at ambient temperature $\left(22-25^{\circ} \mathrm{C}\right)$.

119 The concentration of adsorbent was varied from 0.25 to $1.25 \mathrm{~g} / \mathrm{L}$ to study the individual

120 adsorption isotherms of acenaphthene, NOM, or $\mathrm{Cd}^{2+}$ onto Mag-PCMA-T at pH 7.

121 Additionally, solutions with varying initial concentrations of acenaphthene, $\mathrm{NOM}$, or $\mathrm{Cd}^{2+}$,

122 which ranged from $0.5 \mathrm{mg} / \mathrm{L}$ to $50 \mathrm{mg} / \mathrm{L}$ were treated with the same procedure as above at

$123 \mathrm{pH} 7$ and $5.0 \mathrm{mg}$ Mag-PCMA-T.

124 Simultaneous sorption was conducted with various dosages of Mag-PCMA-T particles

125 (1 mg to $25 \mathrm{mg})$ mixed with $20 \mathrm{~mL}$ of acenaphthene $(1 \mathrm{mg} / \mathrm{L})$ and $\mathrm{Cd}^{2+}(1 \mathrm{mg} / \mathrm{L})$ solution

126 with or without $20 \mathrm{mg} / \mathrm{L}$ NOM present. The influence of solution $\mathrm{pH}$ and ionic strength on

127 the simultaneous removal was investigated by mixing $10 \mathrm{mg}$ of Mag-PCMA-T particles

128 with $20 \mathrm{~mL}$ of acenaphthene and $\mathrm{Cd}^{2+}$ solution $(1 \mathrm{mg} / \mathrm{L})$ under various solution $\mathrm{pH}$ 
129 (ranging from 4 to 10 ) and concentration of $\mathrm{Ca}^{2+}$ or $\mathrm{Mg}^{2+}$ (ranging from $1 \mathrm{mg} / \mathrm{L}$ to

$13050 \mathrm{mg} / \mathrm{L})$, respectively.

131 2.5. Regeneration and reuse of Mag-PCMA-T

132 To investigate the regeneration and reuse of Mag-PCMA-T, a mixed solution with

$1331 \mathrm{mg} / \mathrm{L}$ acenaphthene, $1 \mathrm{mg} / \mathrm{L} \mathrm{Cd}^{2+}$ and $20 \mathrm{mg} / \mathrm{L}$ NOM were used with the same adsorption

134 process, followed by separation of the Mag-PCMA-T from solution with the handheld

135 magnet. The collected Mag-PCMA-T was first rinsed with methanol to extract sorbed

136 acenaphthene and NOM. Then the Mag-PCMA-T was rinsed with $1 \% \mathrm{HCl}$ to extract

137 sorbed $\mathrm{Cd}^{2+}$. The regenerated Mag-PCMA-T particles were then reused for subsequent

138 acenaphthene sorption experiments. The sorption, extraction, and reuse processes were

139 repeated for five times. Changes in sorption capacity was determined at every cycle.

$140 \quad$ 2.6. Analysis

141 An Agilent 7900 inductively coupled plasma with mass spectroscopy (ICP-MS) was

142 used to analyze the concentration of $\mathrm{Cd}^{2+}$. A Shimadzu high performance liquid

143 chromatograph (HPLC) system (SPD-M10AVP, Shimadzu, MD) equipped with an

144 Ascentis C-18 column $(250 \times 4.6 \mathrm{~mm}, 10 \mu \mathrm{m})$ and a UV-Vis spectrometer (BioSpec 1601,

145 Shimadzu, MD) was used for PAHs analysis.

146 Removal efficiency and sorption capacity of PAHs and metal ions was calculated as:

147 Removal efficiency $=\frac{C_{0}-C_{t}}{C_{0}} \times 100 \%$ 
$148 \quad$ Sorption capacity $=q_{e}=\frac{\left(C_{0}-C_{t}\right) \cdot V}{m}$

149 where $C_{0}$ and $C_{t}$ are the initial and final concentrations of PAHs or metal ions $(\mathrm{mg} / \mathrm{L}), \mathrm{m}$

150 is the mass of Mag-PCMA-Ts (g), and $V$ is the volume of solution (L).

151 The equilibrium adsorption of PAHs and metal ions was evaluated according to

152 Langmuir and Freundlich isotherms by Eq. 3 and Eq. 4, respectively (Morel and Hering,

153 1993):

$154 \quad \frac{C_{e}}{q_{e}}=\frac{1}{K_{L} \cdot q_{m}}+\frac{C_{e}}{q_{m}}$

$155 \log q_{e}=\log K_{F}+\frac{1}{n} \log C_{e}$

156 where $C_{e}$ is solute concentration $(\mathrm{mg} / \mathrm{L})$ at equilibrium and $q_{e}$ is amount adsorbed

$157(\mathrm{mg} / \mathrm{g}), q_{m}$ is the maximum sorption capacity $(\mathrm{mg} / \mathrm{g}) . K_{L}(\mathrm{~L} / \mathrm{mg})$ and $K_{F}(\mathrm{mg} / \mathrm{g}) /(\mathrm{L} / \mathrm{mg})^{-\mathrm{n}}$

158 are the Langmuir and Freundlich sorption equilibrium constants, respectively.

159 Kinetics were analyzed using the pseudo-second order model by Eq. 5 (Coleman et al.,

160 1956), since it has been shown to be appropriate for many sorption processes (Ho, 2006;

161 Ho and McKay, 1999; Wu et al., 2009):

$162 \quad \frac{t}{q_{t}}=\frac{1}{k_{2} q_{e}^{2}}+\frac{1}{q_{e}} t$

163 where $k_{2}\left(\frac{g}{m g \cdot h}\right)$ are the equilibrium rate constant of kinetics. 
164 All tests were performed in triplicate and analysis of variance (ANOVA) was used to test

165 the significance of results. A $p<0.05$ was considered to be statistically significant.

166 3. Results and discussion

167 3.1. Characterization of Mag-PCMA-T

168 The core/shell structure of a Mag-PCMA-T is shown in TEM images (Figure 2), and the

169 shell layer (silica porous framework) is approximately $20 \mathrm{~nm}$ as determined by TEM. The

170 size of particles varied from hundreds of nanometers to several micrometers due to

171 aggregation via magnetic forces or crosslinking of the silica framework. The weight

172 percentage of surfactant within the silica framework of Mag-PCMA-T was determined by

173 the difference of initial and final mass of the sample in the TGA measurement and was

174 approximately $7.45 \%$ of the total mass of Mag-PCMA-T. Magnetic characterization by

175 SQUID magnetometer at $300 \mathrm{~K}$ showed that maghemite and Mag-PCMA-T have

176 magnetization saturation values of 52.8 and $14.65 \mathrm{emu} / \mathrm{g}$, respectively (Figure 2C),

177 indicating a relatively high magnetization of Mag-PCMA-T particles even with a thick

178 silica coating. The zeta potential in the initial $\mathrm{pH}$ range of 4 to 10 is presented in Figure 2D

179 for a suspension of Mag-PCMA-T in DI water. In this $\mathrm{pH}$ range, the zeta potential of

180 Mag-PCMA-T is negative (-30.11 to $-41.65 \mathrm{mv})$, and decreases slightly as $\mathrm{pH}$ increases.

181 Even though the surfactant, Triton X-100, is nonionic, due to the pretreatment by TMAOH

182 in the synthesis the surface of maghemite particle was strongly negatively charged (Wang 
183 et al., 2009). It suggests the formation of anionic negatively charged surface complexes on 184 the Mag-PCMA-T particles.
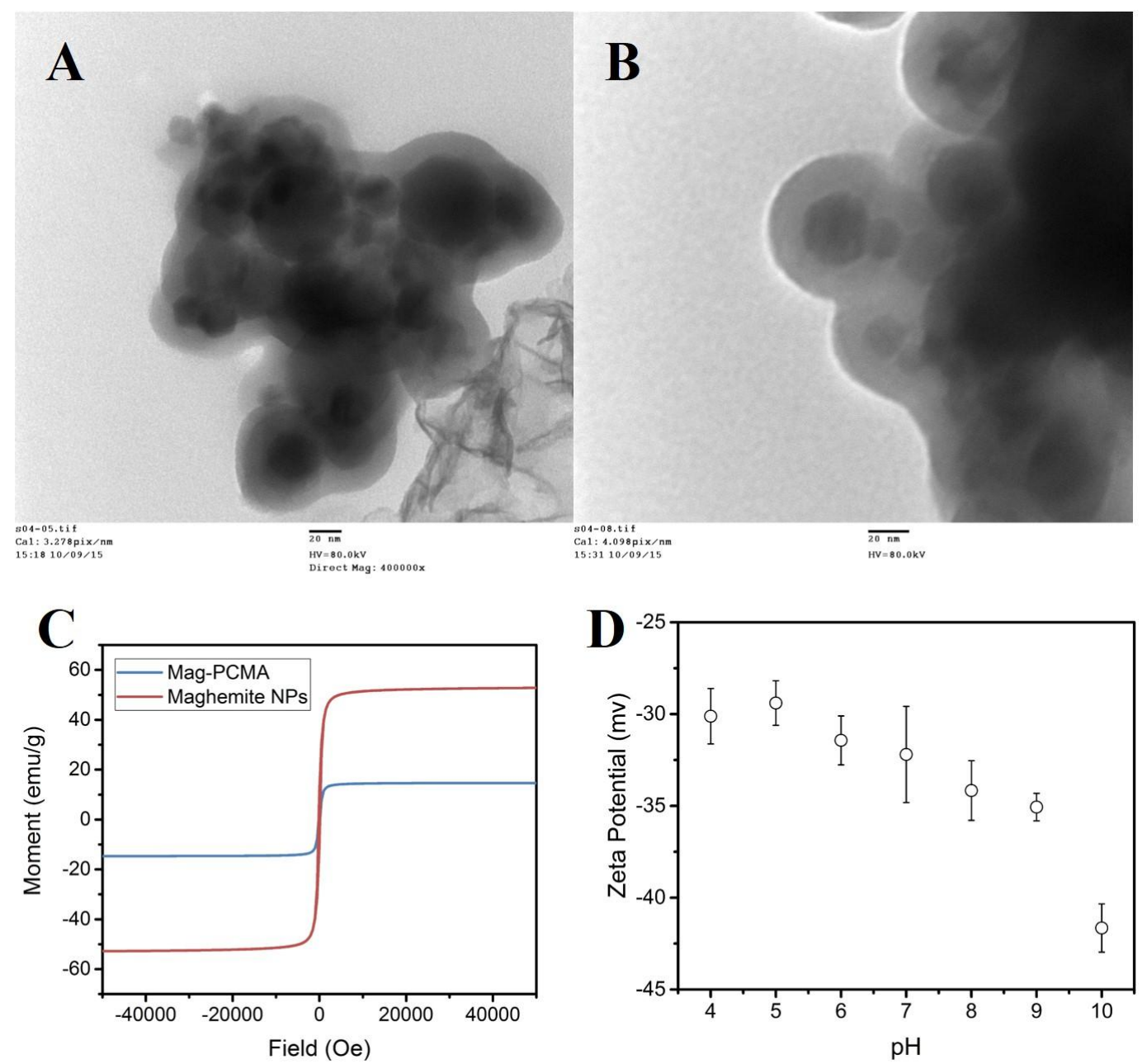

Figure 2. TEM micrographs of Mag-PCMA-T (A) at 400,000 $\times$, scale bar $=20 \mathrm{~nm}$ and

187 (B) at 500,000 $\times$, scale bar=20 nm; (C) the magnetic hysteresis loops of Mag-PCMA-T

188 and maghemite nanoparticles; (D) zeta potential of Mag-PCMA-T particles as a function 189 of $\mathrm{pH}$. 
191 Figure 3 presents the experimental results of the non-competitive sorption for $\mathrm{Cd}^{2+}$,

192 acenaphthene and NOM for the range of concentrations studied, as well as the fit of the

193 Langmuir and Freundlich isotherm model (fitted parameter values are summarized in

194 Table 1). The Langmuir model provided a slightly better fit for $\mathrm{Cd}^{2+}$, while the

195 Freundlich model fitted acenaphthene and NOM adsorption better, based on the

196 correlation coefficients $\left(\mathrm{R}^{2}\right)$ in Table 1 . This suggests a multilayer sorption process

197 (Weber et al., 1991). Since Triton X-100 is a nonionic surfactant confined in micelles

198 within the silica framework of Mag-PCMA-T, there are several potential remediation

199 mechanisms for these three different categories of contaminants. Triton X-100 is a

200 poly(ethylene oxide), and interactions are predominantly between the ethylene oxide

201 groups and the chlorinated and nonchlorinated hydrophobic organic contaminants (Wang

202 and Keller, 2008b; Wang and Keller, 2008c). Due to the hydrophobic cores, the

203 surfactant micelles can enhance the apparent acenaphthene solubility (Rosen and

204 Kunjappu, 2012), which would promote the hydrophobic interaction between

205 acenaphthene and the confined micelles. The ethylene oxide chain on the Triton X-100

206 can form complexes with metal ions (Kikuchi et al., 1992), explaining the sorption of

$207 \mathrm{Cd}^{2+}$ onto Mag-PCMA-Ts. In addition, since the surface of Mag-PCMA-Ts is negatively

208 charged, there are also favorable electrostatic interactions with cationic ions such as $\mathrm{Cd}^{2+}$.

209 NOM consists of both hydrophobic and hydrophilic regions as well as polar groups, such 
210 as carboxylic groups (Tan, 2014). The sorption mechanism of NOM onto Mag-PCMA-T

211 could be the hydrophobic interaction between the hydrophobic fraction of NOM and

212 micelles to enhance the apparent NOM's hydrophobic groups' solubility (Rosen and

213 Kunjappu, 2012) ; or/and the hydrogen bond between carboxylic groups on NOM and

214 poly (ethylene oxide) groups on surfactants (Wang et al., 2011). 

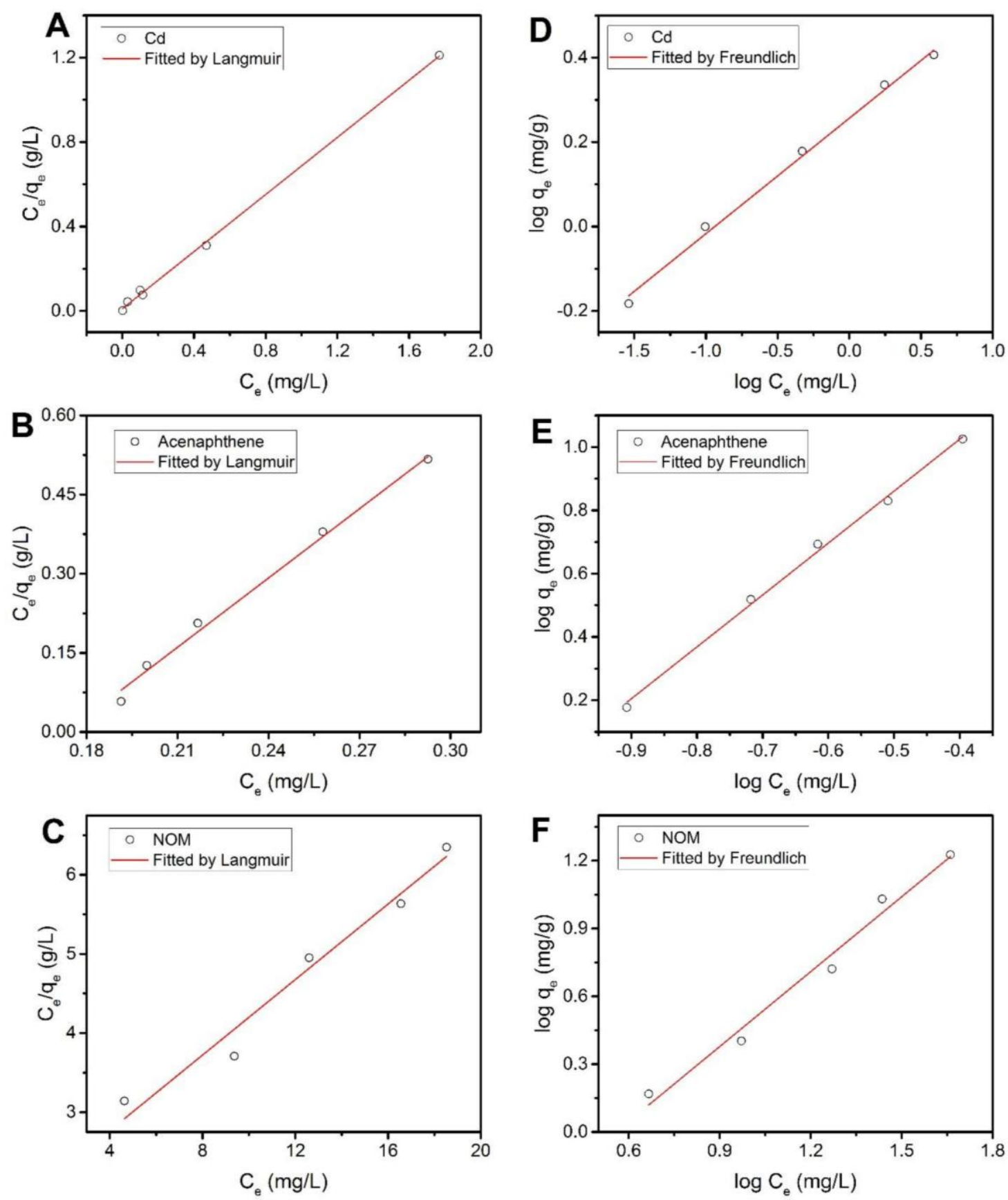

216 Figure 3. Langmuir adsorption isotherms fit for (A) $\mathrm{Cd}^{2+}$; (B) acenaphthene; and (C)

217 NOM onto Mag-PCMA-T at $\mathrm{pH}$ 7; and Freundlich adsorption isotherms fit for (D) $\mathrm{Cd}^{2+}$; 
218 (E) acenaphthene; and (F) NOM onto Mag-PCMA-T at $\mathrm{pH}$ 7, symbols represent

219 experimental data, and red line represents model prediction.

220 Table 1. Isotherm parameters for $\mathrm{Cd}^{2+}$, acenaphthene and NOM sorption on 221 Mag-PCMA-T

\begin{tabular}{lcccccc}
\hline & \multicolumn{3}{c}{ Langmuir } & \multicolumn{4}{c}{ Freundlich } \\
\cline { 2 - 7 } & $\mathrm{q}_{\mathrm{m}}(\mathrm{mg} / \mathrm{g})$ & $\mathrm{K}_{\mathrm{L}}(\mathrm{L} / \mathrm{mg})$ & $\mathrm{R}^{2}$ & $\mathrm{~K}_{\mathrm{F}}\left((\mathrm{mg} / \mathrm{g}) /(\mathrm{L} / \mathrm{mg})^{-\mathrm{n}}\right)$ & $1 / \mathrm{n}$ & $\mathrm{R}^{2}$ \\
\hline $\mathrm{Cd}^{2+}$ & 1.48 & 62.4 & 0.999 & 1.81 & 0.27 & 0.998 \\
Acenaphthene & 0.39 & -10.3 & 0.997 & 48.0 & 1.64 & 0.999 \\
$\mathrm{NOM}$ & 4.19 & 0.13 & 0.908 & 0.24 & 1.10 & 0.991 \\
\hline
\end{tabular}

\subsection{Sorption kinetics of PAHs and metal contaminants}

223 Time dependent removal of acenaphthene and $\mathrm{Cd}^{2+}$ (initial concentration $=1 \mathrm{mg} / \mathrm{L}$ ) by

224 Mag-PCMA-T $(0.25 \mathrm{~g} / \mathrm{L})$ showed rapid adsorption of acenaphthene and $\mathrm{Cd}^{2+}$; around

$22595 \%$ of the maximum sorption capacities were obtained in the first $30 \mathrm{~min}$, as shown in

226 Figure 4A. The pseudo-second order (Figure 4B and C) kinetic model was used to

227 investigate the adsorption rate of acenaphthene and $\mathrm{Cd}^{2+}$ onto Mag-PCMA-Ts, and the

228 kinetic parameters were listed in Table 2. Mag-PCMA-T's fast sorption kinetics for both

229 acenaphthene and $\mathrm{Cd}^{2+}$ is due to the relatively high portion of the confined surfactant

230 micelles. It also indicates the silica framework did not show significant effect on the

231 diffusion of PAHs and metal contaminants into the micelles. 

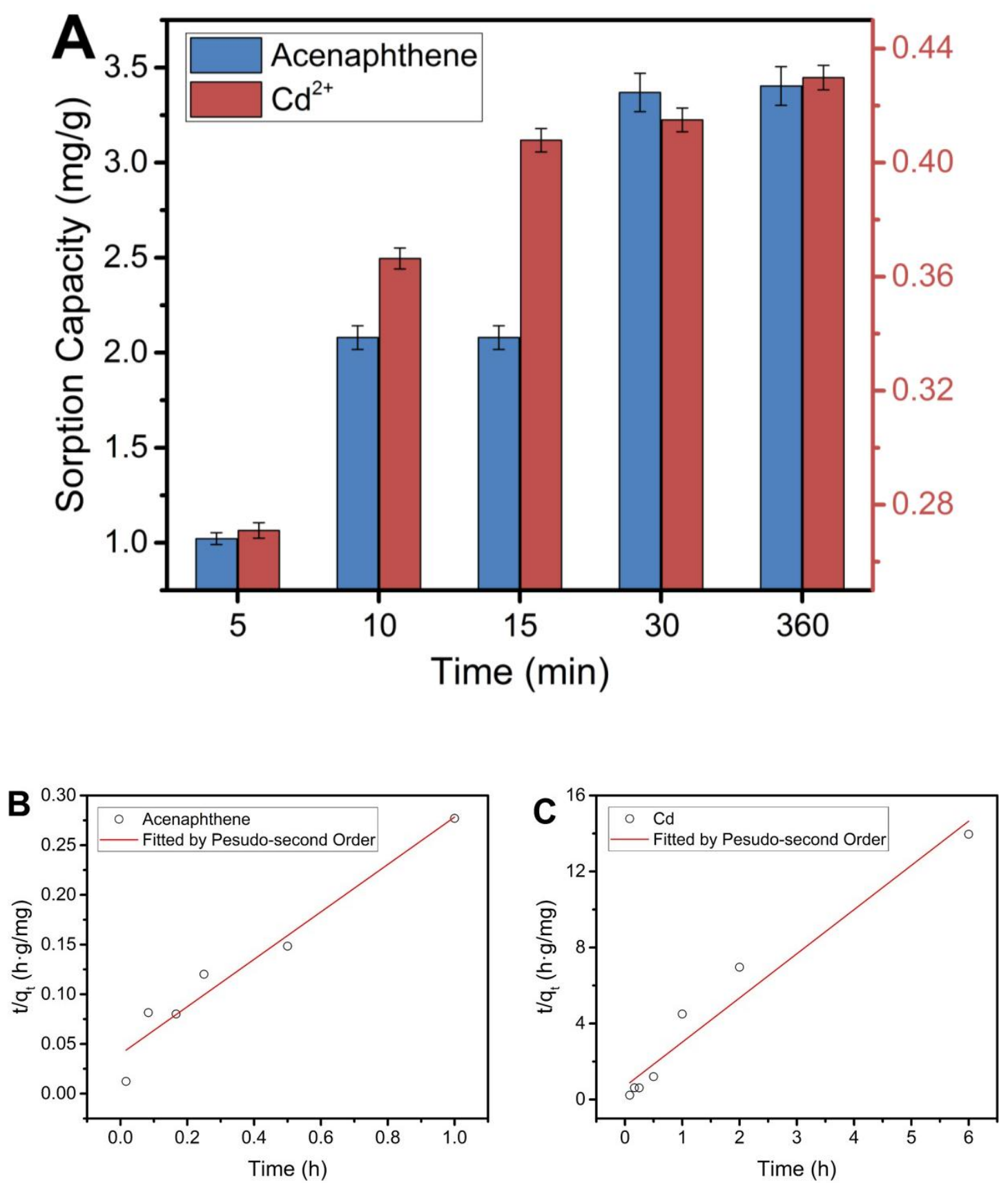

Figure 4. (A) Sorption capacity of acenaphthene and $\mathrm{Cd}^{2+}$ versus time; and sorption

235 kinetics fitted by pseudo-second order of (B) acenaphthene; (C) $\mathrm{Cd}^{2+}$ onto Mag-PCMA-T 
236 in solution at $\mathrm{pH} 7$, symbols represent experimental data, and red line represents model

237 prediction.

238 Table 2. Kinetic parameters for $\mathrm{Cd}^{2+}$ and acenaphthene sorption on Mag-PCMA-T

\begin{tabular}{lccc}
\hline & $\mathrm{q}_{\mathrm{e}}(\mathrm{mg} / \mathrm{g})$ & $\mathrm{k}_{2}(\mathrm{~g} / \mathrm{h} \cdot \mathrm{mg})$ & $\mathrm{R}^{2}$ \\
\hline $\mathrm{Cd}^{2+}$ & 0.78 & 0.98 & 0.978 \\
Acenaphthene & 4.19 & 1.43 & 0.975 \\
\hline
\end{tabular}

\subsection{Simultaneous sorption of PAHs, metal contaminants and NOM}

240 Based on the above studies, Mag-PCMA-T can remove POPs, metals and NOM from

241 contaminated water. Thus, there is the potential for simultaneous remediation of these

242 contaminants (POPs and metals) even in the presence of NOM, which usually would

243 affect the adsorption behavior (Luo et al.). The simultaneous removal of acenaphthene

244 and $\mathrm{Cd}^{2+}$ is presented in Figure 5. Compared to the individual sorption of acenaphthene

245 or $\mathrm{Cd}^{2+}$, the sorption capacities decreased, indicating some competitive sorption between

246 acenaphthene and $\mathrm{Cd}^{2+}$. It results from the fact that both acenaphthene and $\mathrm{Cd}^{2+}$ interact

247 with the poly(ethylene oxide) groups on the surfactant micelles (Kikuchi et al., 1992;

248 Wang and Keller, 2008b; Wang and Keller, 2008c), given that the number of the reactive

249 sites is limited. Competitive sorption is also evidenced by the fact that as Mag-PCMA-T

250 dosage increased, the differences in sorption capacity between individual and

251 simultaneous sorption decreased. Noticeably, competitive sorption results in less impact 
252 on the adsorption capacity of acenaphthene than on $\mathrm{Cd}^{2+}$. This can be explained by the

253 faster sorption kinetics on acenaphthene, based on the kinetic constant $\mathrm{k}_{2}$ (Table 2),

254 which allows acenaphthene to occupy the available active sites first. This result also

255 agrees with the fact that the difference was less significant with higher Mag-PCMA-T

256 dosage, since there are more available sites.

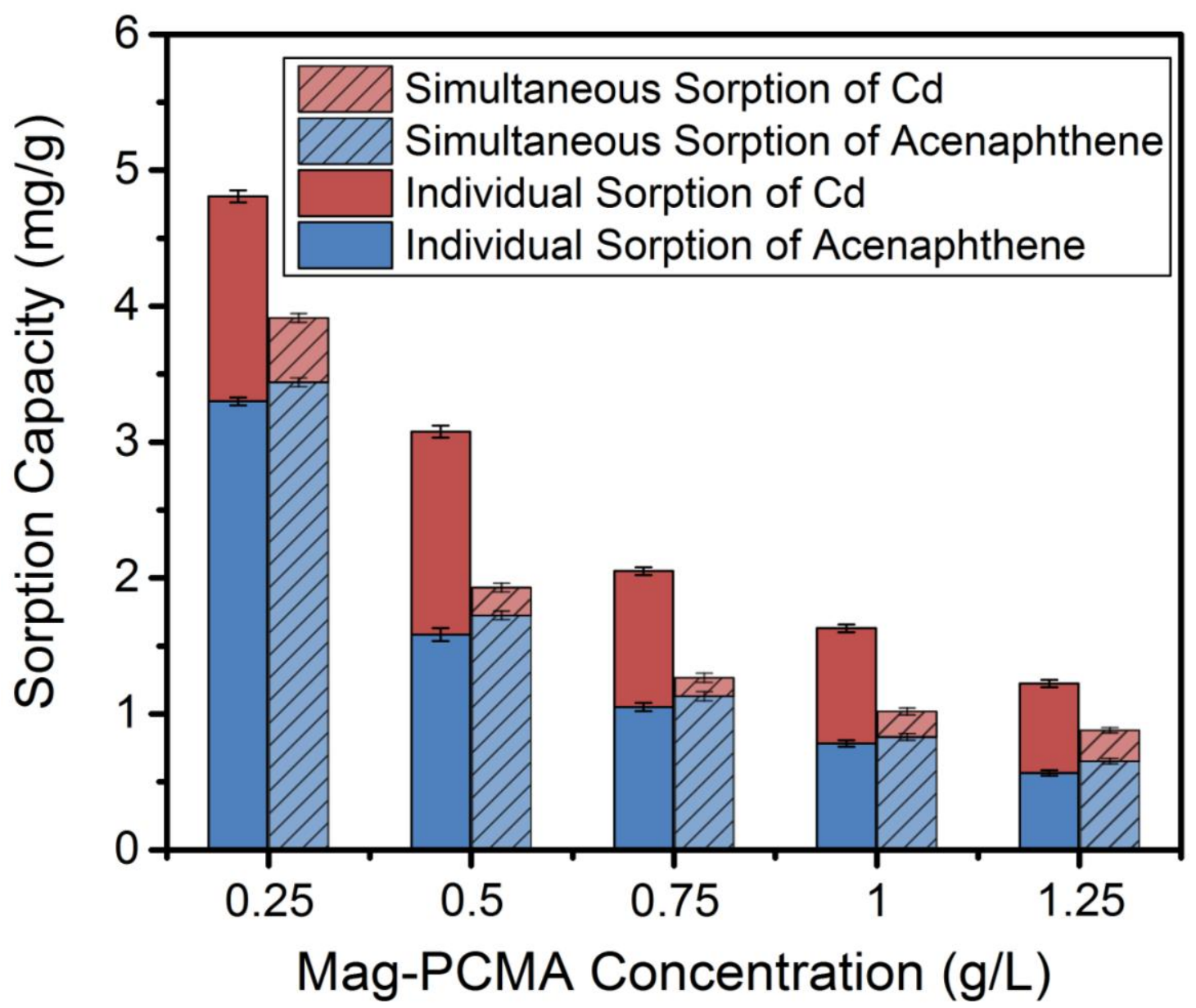

258 Figure 5. Simultaneous sorption of $\mathrm{Cd}^{2+}$ and acenaphthene as a function of adsorbent

259 dose with a fixed initial concentration of $1 \mathrm{mg} / \mathrm{L} \mathrm{Cd}^{2+}$ and acenaphthene equally. 
260 Individual sorption capacity of $\mathrm{Cd}^{2+}$ and acenaphthene under same conditions are 261 presented for comparison.

262 Furthermore, as NOM constitutes a major fraction of the organic matter in water, the 263 simultaneous sorption of $\mathrm{Cd}^{2+}$ and acenaphthene in the presence of NOM was also 264 investigated, as shown in Figure 6. The sorption capacity of Mag-PCMA-T for 265 acenaphthene decreased slightly in the presence of NOM. This is not surprising because 266 NOM also competes for the limited ethylene oxide groups on the surfactant micelles.

267 Also, the concentration of NOM $(20 \mathrm{mg} / \mathrm{L})$ was much higher than acenaphthene, which 268 increases the driving force and results in higher sorption of NOM. On the other hand, the 269 sorption capacity of $\mathrm{Cd}^{2+}$ increased in the presence of NOM, since a significant amount 270 of polar groups (e.g. carboxylic groups) on NOM (Tan, 2014) can also complex $\mathrm{Cd}^{2+}$

271 (Otto et al., 2001). The differences were smaller when a higher amount of Mag-PCMA-T 272 was added. 


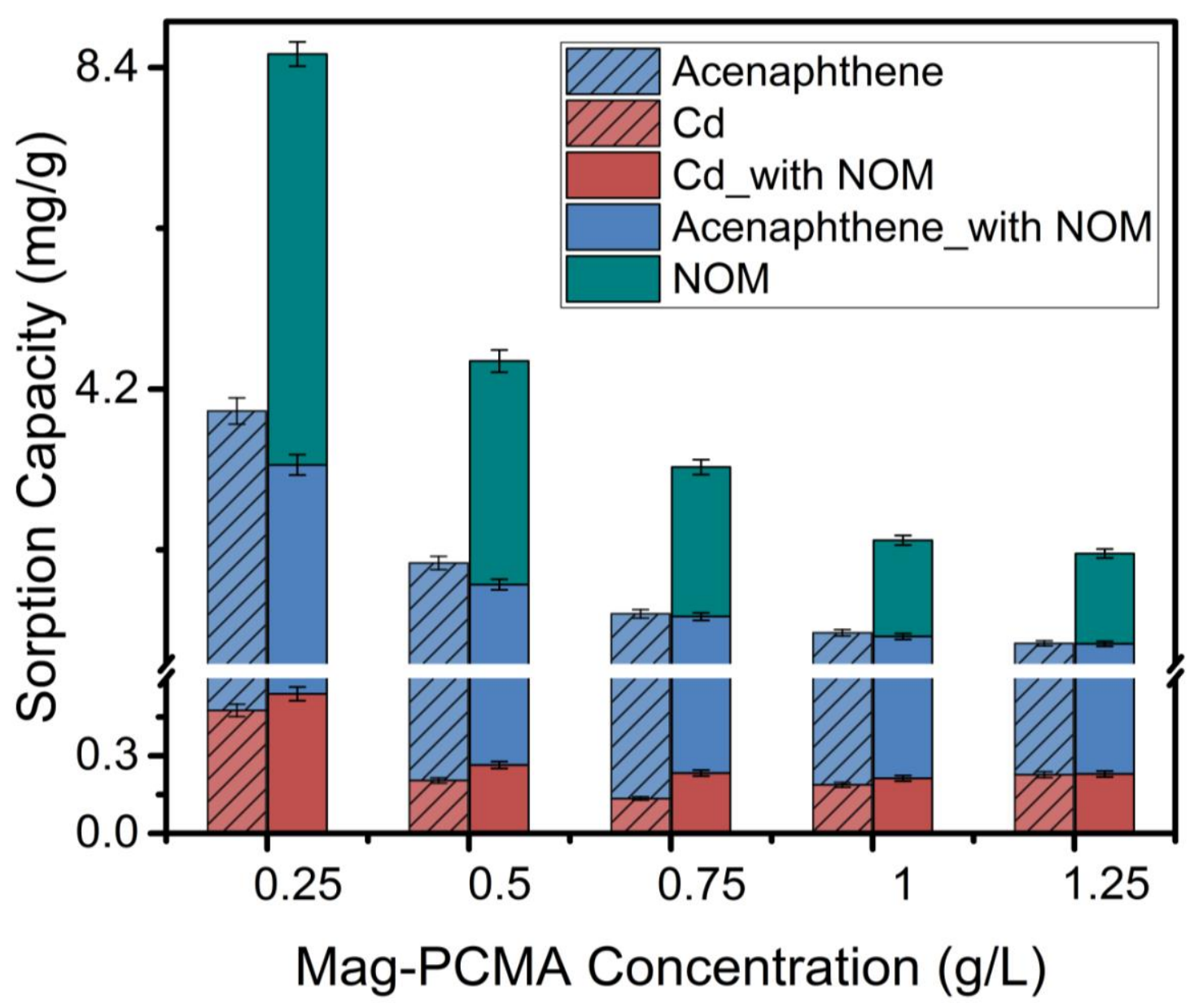

274 Figure 6. Simultaneous sorption of $\mathrm{Cd}^{2+}$, acenaphthene and NOM as a function of

275 adsorbent dose with a fixed initial concentration of $1 \mathrm{mg} / \mathrm{L}$ of $\mathrm{Cd}^{2+}$ and acenaphthene

276 equally in the presence of $20 \mathrm{mg} / \mathrm{L}$ NOM.

277 3.5. Effect of $\mathrm{pH}$ on simultaneous removal

$278 \mathrm{pH}$ is an important factor in water chemistry, which may affect the speciation of solutes

279 as well as the surface charge of adsorbents. In Figure 7, as $\mathrm{pH}$ increased, the

280 simultaneous sorption of both $\mathrm{Cd}^{2+}$ and acenaphthene increased, with a particularly

281 significant increase in $\mathrm{Cd}^{2+}$ sorption. As indicated in Figure 2D, the surface of 
282 Mag-PCMA-T is increasingly more negatively charged as $\mathrm{pH}$ increases. Simulation of 283 the aqueous speciation of cadmium, using Visual MINTEQ (Gustafsson, 2006) software, 284 indicates that for $\mathrm{pH}$ from 3 to 10 , cadmium in DI water at these concentrations is mostly 285 present as $\mathrm{Cd}^{2+}$, which is favorable for the electrostatic interactions with Mag-PCMA-T's 286 negatively charged surface across this $\mathrm{pH}$ range. It suggests that the dominant mechanism 287 of $\mathrm{Cd}^{2+}$ remediation by Mag-PCMA-T is electrostatic interaction. The slight increase in 288 the removal on acenaphthene indicates that the major removal path for HOCs is via 289 hydrophobic interactions between the confined surfactant micelles and HOCs (Edwards 290 et al., 1991), and electronic forces has less impact. There could be a slight rearrangement 291 of the surfactant micelles with increasing $\mathrm{pH}$, leading to slightly more sorption capacity 292 for HOCs on the hydrophobic surfaces of Triton-X. Since acenaphthene has a very high $293 \mathrm{pK}_{\mathrm{a}}$ value (>15) (Montgomery, 2007), higher than the range of $\mathrm{pH}(4.0-10.0)$ considered 294 in the current study, it is neutral within the $\mathrm{pH}$ range (Atkins and De Paula). 


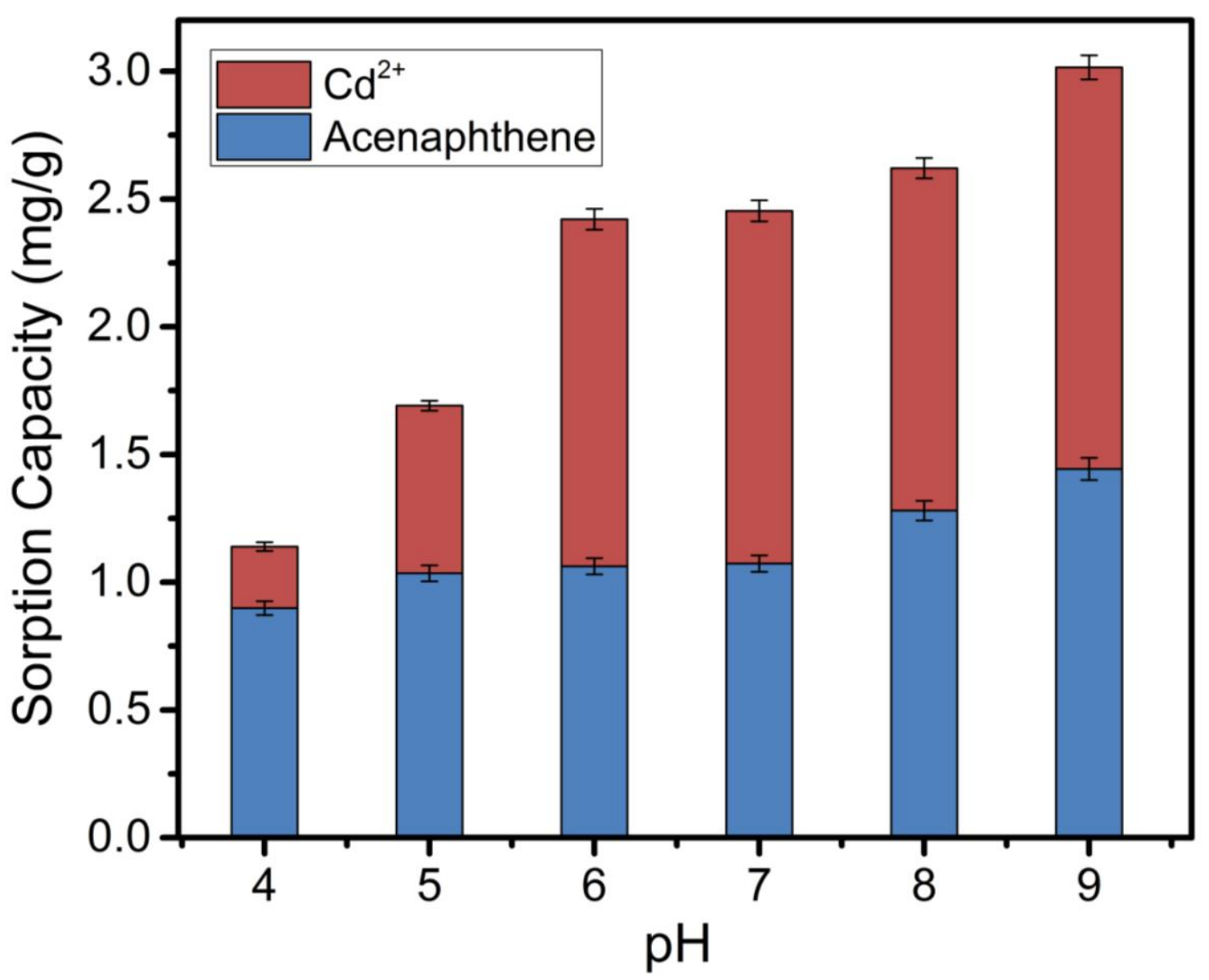

296 Figure 7. Simultaneous sorption of $\mathrm{Cd}^{2+}$ and acenaphthene as a function of $\mathrm{pH}$.

297 3.6. Effect of water hardness on simultaneous removal

298 Water hardness is usually expressed as the total amount of $\mathrm{Ca}^{2+}$ and $\mathrm{Mg}^{2+}$ present in the 299 water, which varies in different water matrices. As complexes between poly(ethylene 300 oxide) groups on the surfactant micelles and metal ions are not specific, thus, $\mathrm{Ca}^{2+}$ and $301 \mathrm{Mg}^{2+}$ may also compete with simultaneous sorption of $\mathrm{Cd}^{2+}$ and acenaphthene (Kikuchi et 302 al., 1992). Figure 8 shows the simultaneous removal performance of $\mathrm{Cd}^{2+}$ and 303 acenaphthene using Mag-PCMA-T in the presence of different concentrations of $\mathrm{Ca}^{2+}$ or 
$304 \mathrm{Mg}^{2+}$. No significant difference was found on the sorption capacity of acenaphthene with

305 either $\mathrm{Ca}^{2+}$ or $\mathrm{Mg}^{2+}$ concentrations up to $50 \mathrm{mg} / \mathrm{L}$. However, the sorption capacity of $\mathrm{Cd}^{2+}$

306 sharply decreased when more $\mathrm{Mg}^{2+}$ was present, while no obvious change was observed

307 with $\mathrm{Ca}^{2+}$ presence. Previous studies indicate that alkaline earth metal ion and $\mathrm{Ca}^{2+}$

308 complexes with Triton X-100 showed low formation constant (Kikuchi et al., 1992),

309 suggesting less competitive sorption would be observed between $\mathrm{Cd}^{2+}$ and $\mathrm{Ca}^{2+}$.

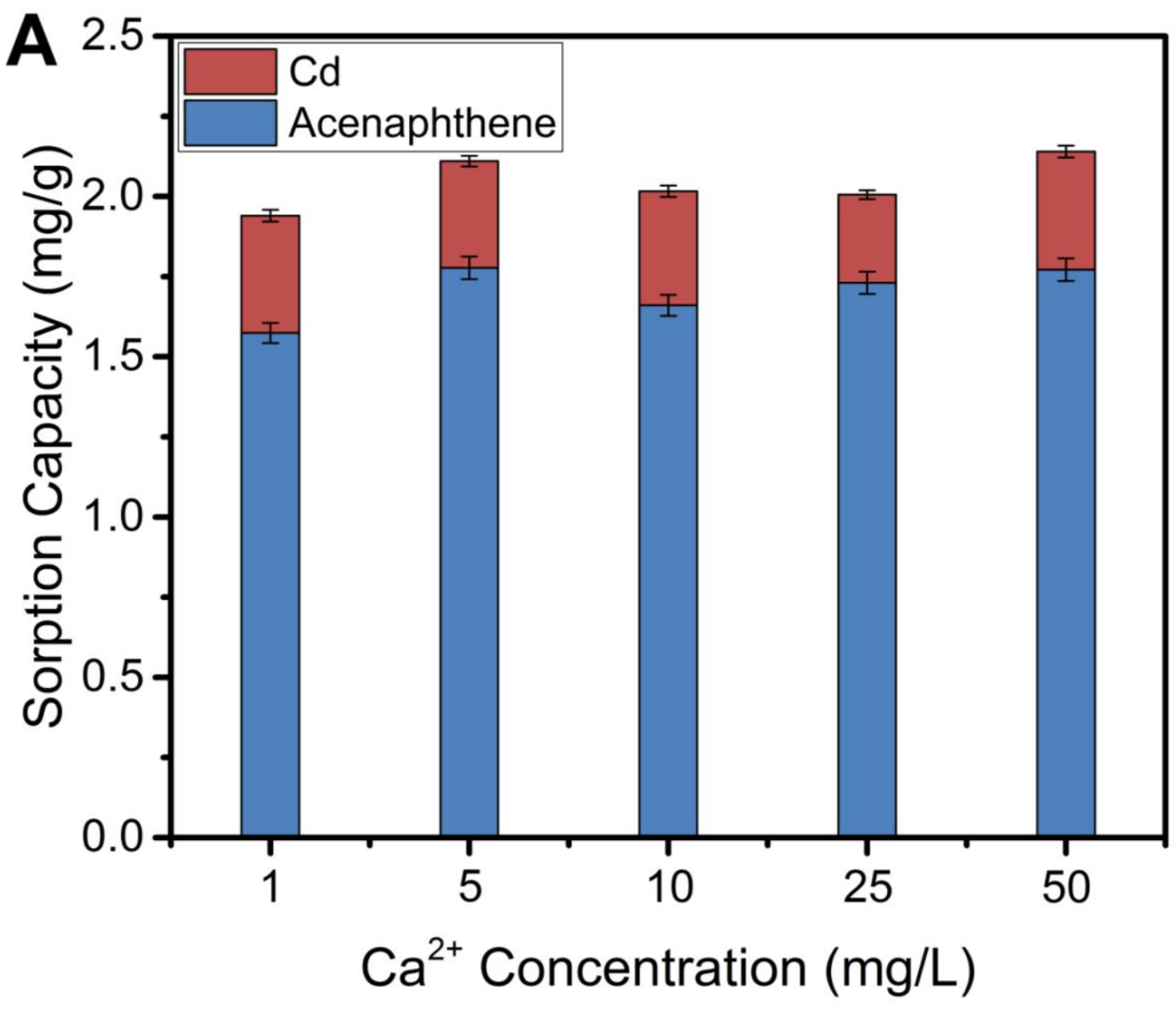




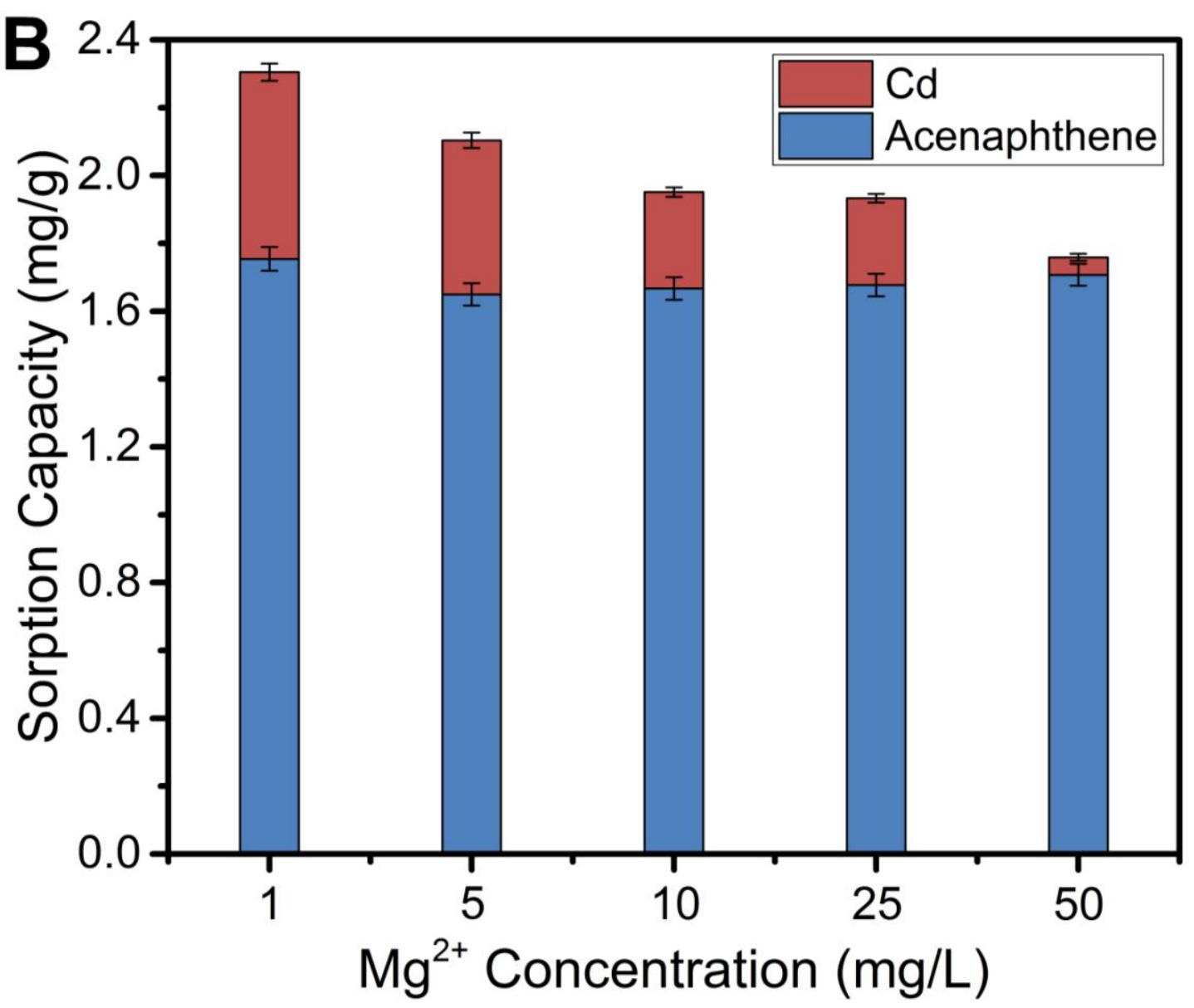

313 Figure 8. Simultaneous sorption of $\mathrm{Cd}^{2+}$ and acenaphthene in the presence of (A)

$314 \mathrm{Ca}^{2+}$ (from $1 \mathrm{mg} / \mathrm{L}$ to $50 \mathrm{mg} / \mathrm{L}$ ) and (B) $\mathrm{Mg}^{2+}$ (from $1 \mathrm{mg} / \mathrm{L}$ to $50 \mathrm{mg} / \mathrm{L}$ ) at $\mathrm{pH} 7$.

315 3.7. Regeneration and reuse of Mag-PCMA-T

316 To demonstrate the regenerability and reusability of the Mag-PCMA-T, the recovery of

317 acenaphthene and NOM sorbed onto the Mag-PCMA-T was investigated using methanol

318 extraction while the adsorbed $\mathrm{Cd}^{2+}$ was extracted by dilute acid $(1 \% \mathrm{HCl})$. The

319 simultaneous removal performance of acenaphthene, NOM and $\mathrm{Cd}^{2+}$ mixed

320 solution during five continuous cycles of regeneration and reuse are shown in Figure 9. No 
321 significant losses of sorption capacity of all these three compounds was observed for the 322 regenerated Mag-PCMA-T up to 5 cycles, indicating good reusability of Mag-PCMA-T.

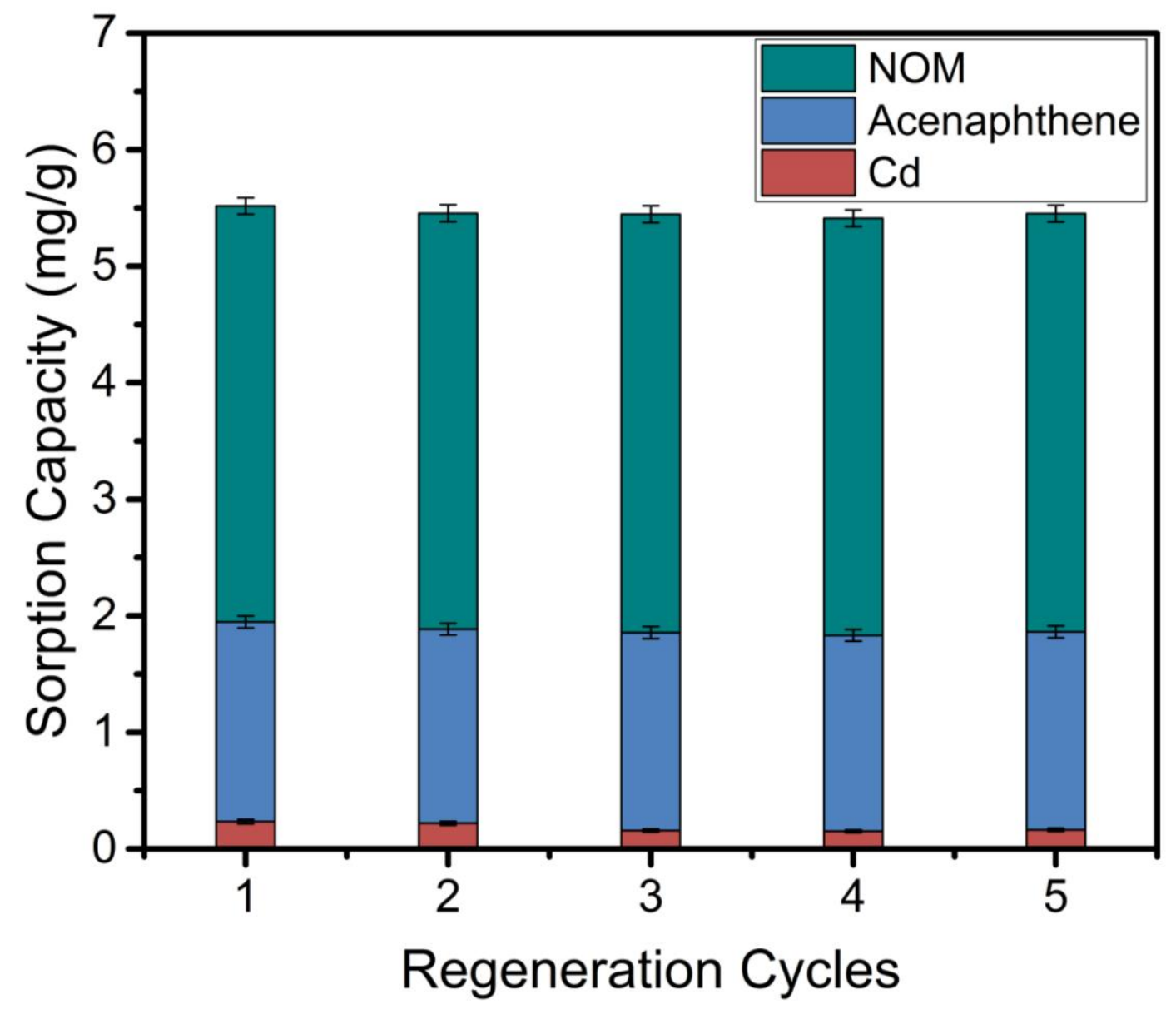

324 Figure 9. Sorption of acenaphthene onto Mag-PCMA-T during five regeneration 325 cycles.

\section{4. Conclusions}

327 Micelle array permanently confined magnetic nanoparticle adsorbents with nonionic 328 surfactant were successfully synthesized with Triton X-100 (Mag-PCMA-T), and the 329 novel adsorbents performed well to remove $\mathrm{Cd}^{2+}$, acenaphthene and NOM, individually 
330 and simultaneously. The isotherm study indicated that hydrophobic interactions played an

331 important role in the sorption process of acenaphthene while a complexation reaction is

332 the most likely dominant mechanism for $\mathrm{Cd}^{2+}$ sorption. The kinetic study showed that

333 sorption of PAHs and metal contaminants by Mag-PCMA-T was rapid. Mag-PCMA-T

334 can simultaneously remove $\mathrm{Cd}^{2+}$ and acenaphthene with or without NOM present. The

335 simultaneous sorption of $\mathrm{Cd}^{2+}$ and acenaphthene by Mag-PCMA-Ts was not significantly

336 affected by the change of water hardness and increased with an increase of $\mathrm{pH}$. Moreover,

337 the adsorbent exhibited excellent regeneration performance and can be used for

338 simultaneous removal of $\mathrm{Cd}^{2+}, \mathrm{NOM}$ and acenaphthene several times without significant

339 loss of sorption capacity. We demonstrated that Mag-PCMA-T can provide a fast,

340 effective and more sustainable approach for simultaneous decontamination of PAHs,

341 metal ions and NOM.

342 ACKNOWLEDGEMENTS

343 This work made use of MRL Central Facilities supported by the MRSEC Program of the

344 National Science Foundation under awards NO. DMR 1121053; a member of the

345 NSF-funded Materials Research Facilities Network (www.mrfn.org). We thank the MRL

346 Central Facilities for the use of their TGA and SQUID instruments as well as Amanda 
347 Strom and Paige Roberts at the UCSB MRL for their help with these instruments. AAK

348 also appreciates Agilent Technologies for their Agilent Thought Leader Award. 
References:

351

352

353

354

355

356

357

358

359

360

361

362

363

364

365

366

367

368

369

370

371

372

373

374

375

376

377

378

379

380

381

382

383

384

385

Adeleye AS, Conway JR, Garner K, Huang Y, Su Y, Keller AA. Engineered nanomaterials for water treatment and remediation: Costs, benefits, and applicability. Chemical Engineering Journal 2016; 286: 640-662.

Atkins P, De Paula J. Physical chemistry, 2002. Oxford University Press, ca; 57: 80.

Chen C-F, Binh NT, Chen C-W, Dong C-D. Removal of polycyclic aromatic hydrocarbons from sediments using sodium persulfate activated by temperature and nanoscale zero-valent iron. Journal of the Air \& Waste Management Association 2015; 65: 375-383.

Clark KK, Keller AA. Adsorption of perchlorate and other oxyanions onto magnetic permanently confined micelle arrays (Mag-PCMA-T). Water research 2012a; 46: 635-644.

Clark KK, Keller AA. Investigation of two magnetic permanently confined micelle array sorbents using nonionic and cationic surfactants for the removal of PAHs and pesticides from aqueous media. Water, Air, \& Soil Pollution 2012b; 223: 3647-3655.

Coleman NT, Mcclung AC, Moore DP. Formation Constants for Cu(Ii)-Peat Complexes. Science 1956; 123: 330-331.

Edwards DA, Luthy RG, Liu ZB. Solubilization of Polycyclic Aromatic-Hydrocarbons in Micellar Nonionic Surfactant Solutions. Environmental Science \& Technology 1991; 25: 127-133.

Feng SL, Mai BX, Wei GJ, Wang XM. Genotoxicity of the sediments collected from Pearl River in China and their polycyclic aromatic hydrocarbons (PAHs) and heavy metals. Environmental Monitoring and Assessment 2012; 184: 5651-5661.

Gustafsson JP. Visual minteq. Capturado em de 2006; 26.

Hanna K, Beurroies I, Denoyel R, Desplantier-Giscard D, Galarneau A, Di Renzo F. Sorption of hydrophobic molecules by organic/inorganic mesostructures. Journal of Colloid and Interface Science 2002; 252: 276-283.

Ho Y-S. Review of second-order models for adsorption systems. Journal of hazardous materials 2006; 136: 681-689.

Ho Y-S, McKay G. Pseudo-second order model for sorption processes. Process biochemistry 1999; 34: 451-465.

Huang Y, Fulton AN, Keller AA. Optimization of porous structure of superparamagnetic nanoparticle adsorbents for higher and faster removal of emerging organic contaminants and PAHs. Environmental Science: Water Research \& Technology 2016. 
Huang Y, Keller AA. Magnetic Nanoparticle Adsorbents for Emerging Organic Contaminants. ACS Sustainable Chemistry \& Engineering 2013; 1: 731-736.

Huang Y, Keller AA. EDTA functionalized magnetic nanoparticle sorbents for cadmium and lead contaminated water treatment. Water Research 2015; 80: 159-168.

Huang Y, Yang J-K, Keller AA. Removal of Arsenic and Phosphate from Aqueous Solution by Metal (Hydr-)oxide Coated Sand. ACS Sustainable Chemistry \& Engineering 2014; 2: 1128-1138.

Hübner R, Astin KB, Herbert RJ. 'Heavy metal' - time to move on from semantics to pragmatics? Journal of Environmental Monitoring 2010; 12: 1511-1514.

Hung P-C, Chang S-H, Ou-Yang C-C, Chang M-B. Simultaneous removal of PCDD/Fs, pentachlorophenol and mercury from contaminated soil. Chemosphere 2016; 144: 50-58.

Kikuchi Y, Suzuki T, Sawada K. Liquid-liquid extraction of alkaline earth metal ions with a non-ionic surfactant having a poly (oxyethylene) chain (Triton X-100). Analytica chimica acta 1992; 264: 65-70.

Lalhmunsiama, Tiwari D, Lee S-M. Surface-functionalized activated sericite for the simultaneous removal of cadmium and phenol from aqueous solutions: Mechanistic insights. Chemical Engineering Journal 2016; 283: 1414-1423.

Lee H, Jang Y, Lee YM, Lee H, Kim G-H, Kim J-J. Enhanced removal of PAHs by Peniophora incarnata and ascertainment of its novel ligninolytic enzyme genes. Journal of environmental management 2015; 164: 10-18.

Liu W, Sun W, Borthwick AGL, Wang T, Li F, Guan Y. Simultaneous removal of Cr(VI) and 4-chlorophenol through photocatalysis by a novel anatase/titanate nanosheet composite: Synergetic promotion effect and autosynchronous doping. Journal of Hazardous Materials 2016; 317: 385-393.

Luo C, Liu C, Wang Y, Liu X, Li F, Zhang G, et al. Heavy metal contamination in soils and vegetables near an e-waste processing site, south China. Journal of Hazardous Materials 2011; 186: 481-490.

Luo F, Chen Z, Megharaj M, Naidu R. Simultaneous removal of trichloroethylene and hexavalent chromium by green synthesized agarose-Fe nanoparticles hydrogel. Chemical Engineering Journal 2016; 294: 290-297.

Luo M, Huang Y, Zhu M, Tang Y-n, Ren T, Ren J, et al. Properties of different natural organic matter influence the adsorption and aggregation behavior of $\mathrm{TiO} 2$ nanoparticles. Journal of Saudi Chemical Society.

Ma L, Chen Q, Zhu J, Xi Y, He H, Zhu R, et al. Adsorption of phenol and Cu(II) onto cationic and zwitterionic surfactant modified montmorillonite in single and binary systems. Chemical Engineering Journal 2016a; 283: 880-888. 
Ma L, Zhu J, Xi Y, Zhu R, He H, Liang X, et al. Adsorption of phenol, phosphate and $\mathrm{Cd}(\mathrm{II})$ by inorganic-organic montmorillonites: A comparative study of single and multiple solute. Colloids and Surfaces A: Physicochemical and Engineering Aspects 2016b; 497: 63-71.

Montgomery JH. Groundwater chemicals desk reference: CRC Press, 2007.

Morel FMM, Hering JG. Principles and Applications of Aquatic Chemistry: Wiley, 1993.

Mulligan CN, Yong RN, Gibbs BF, James S, Bennett HPJ. Metal removal from

contaminated soil and sediments by the biosurfactant surfactin. Environmental Science \& Technology 1999; 33: 3812-3820.

Otto WH, Burton SD, Carper WR, Larive CK. Examination of cadmium (II) complexation by the Suwannee River fulvic acid using 113Cd NMR relaxation measurements. Environmental science \& technology 2001; 35: 4900-4904.

Rosen MJ, Kunjappu JT. Surfactants and interfacial phenomena: John Wiley \& Sons, 2012.

Sargin İ, Kaya M, Arslan G, Baran T, Ceter T. Preparation and characterisation of biodegradable pollen-chitosan microcapsules and its application in heavy metal removal. Bioresource technology 2015; 177: 1-7.

Su Y, Adeleye AS, Huang Y, Sun X, Dai C, Zhou X, et al. Simultaneous removal of cadmium and nitrate in aqueous media by nanoscale zerovalent iron (nZVI) and Au doped nZVI particles. Water Research 2014; 63: 102-111.

Su Y, Adeleye AS, Huang Y, Zhou X, Keller AA, Zhang Y. Direct Synthesis of Novel and Reactive Sulfide-modified Nano Iron through Nanoparticle Seeding for Improved Cadmium-Contaminated Water Treatment. Scientific Reports 2016; 6: 24358.

Su Y, Adeleye AS, Keller AA, Huang Y, Dai C, Zhou X, et al. Magnetic sulfide-modified nanoscale zerovalent iron (S-nZVI) for dissolved metal ion removal. Water Research 2015; 74: 47-57.

Tan KH. Humic matter in soil and the environment: principles and controversies: CRC Press, 2014.

Thavamani P, Megharaj M, Naidu R. Multivariate analysis of mixed contaminants (PAHs and heavy metals) at manufactured gas plant site soils. Environmental Monitoring and Assessment 2012; 184: 3875-3885.

Vela N, Martinez-Menchon M, Navarro G, Perez-Lucas G, Navarro S. Removal of polycyclic aromatic hydrocarbons (PAHs) from groundwater by heterogeneous photocatalysis under natural sunlight. Journal of Photochemistry and Photobiology a-Chemistry 2012; 232: 32-40. 
Wang H, Keller AA, Clark KK. Natural organic matter removal by adsorption onto magnetic permanently confined micelle arrays. Journal of hazardous materials 2011; 194: 156-161.

Wang P, Keller AA. Adsorption of hydrophobic organic compounds onto a hydrophobic carbonaceous geosorbent in the presence of surfactants. Environmental Toxicology and Chemistry 2008a; 27: 1237-1243.

Wang P, Keller AA. Particle-size dependent sorption and desorption of pesticides within a water-soil-nonionic surfactant system. Environmental Science \& Technology 2008b; 42: 3381-3387.

Wang P, Keller AA. Partitioning of hydrophobic organic compounds within soil-water-surfactant systems. Water Research 2008c; 42: 2093-2101.

Wang P, Shi QH, Shi YF, Clark KK, Stucky GD, Keller AA. Magnetic Permanently Confined Micelle Arrays for Treating Hydrophobic Organic Compound Contamination. Journal of the American Chemical Society 2009; 131: 182-188.

Weber WJ, Mcginley PM, Katz LE. Sorption Phenomena in Subsurface Systems Concepts, Models and Effects on Contaminant Fate and Transport. Water Research 1991; 25: 499-528.

Wu F-C, Tseng R-L, Huang S-C, Juang R-S. Characteristics of pseudo-second-order kinetic model for liquid-phase adsorption: A mini-review. Chemical Engineering Journal 2009; 151: 1-9.

Zhang J, Gong J-L, Zenga G-M, Ou X-M, Jiang Y, Chang Y-N, et al. Simultaneous removal of humic acid/fulvic acid and lead from landfill leachate using magnetic graphene oxide. Applied Surface Science 2016; 370: 335-350. 
Graphical Abstract
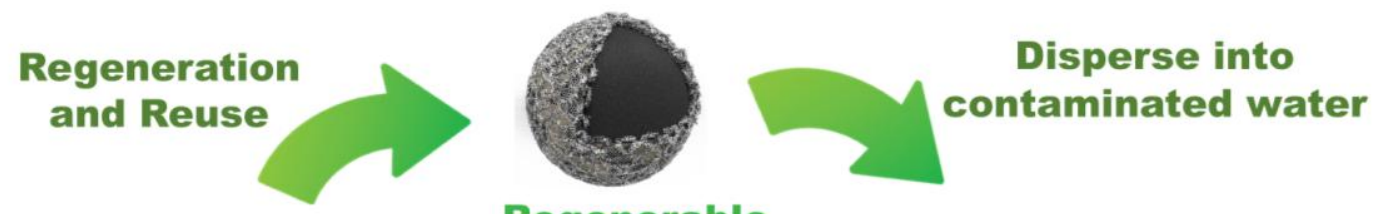

Regenerable

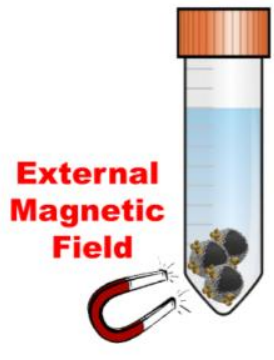

Mag-PCMA NP Sorbents

Magnetic
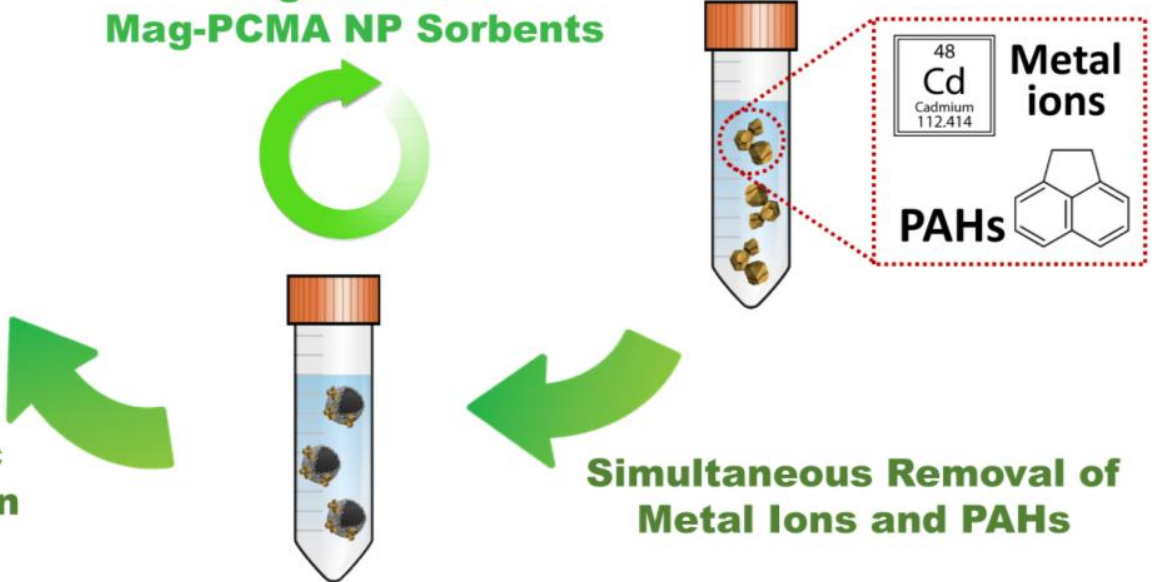

Separation

Simultaneous Removal of Metal Ions and PAHs 